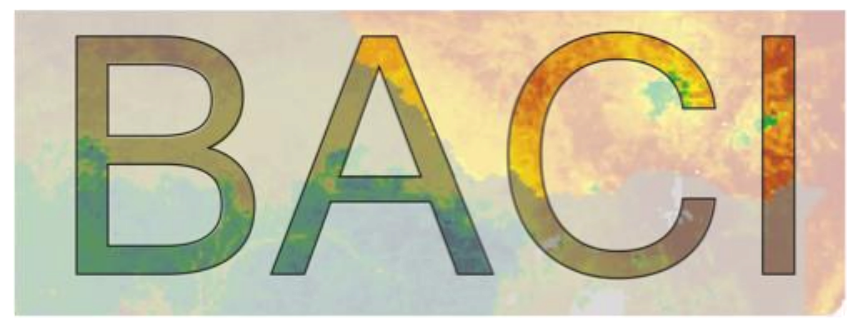

\title{
SMOS retrieval over forests: Exploitation of optical depth and tests of soil moisture estimates
}

\section{Postprint version}

Vittucci, C., Ferrazzoli, P., Kerr, Y., Richaume, P., Guerriero, L., Rahmoune, R., et al.

\section{Published in: Remote Sensing of Environment}

Reference: Vittucci, C., Ferrazzoli, P., Kerr, Y., Richaume, P., Guerriero, L., Rahmoune, R., et al. (2016). SMOS retrieval over forests: Exploitation of optical depth and tests of soil moisture estimates. Remote Sensing of Environment, 180, 115-127. doi:10.1016/j.rse.2016.03.004

Web link: $\quad$ https://www.sciencedirect.com/science/article/pii/S0034425716300979 


\title{
SMOS retrieval over forests: Exploitation of optical depth and tests of soil moisture estimates
}

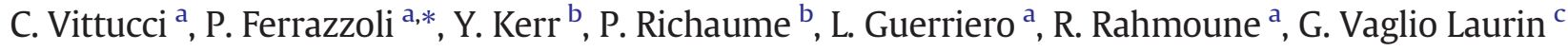 \\ a University of Rome Tor Vergata, DICII, Rome, Italy \\ b CESBIO (CNES, CNRS, IRD, UPS) Toulouse, France \\ c Tuscia University, DIBAF, Viterbo, Italy
}

\begin{abstract}
A B S T R A C T
This research aims to test data obtained by level 2 retrieval algorithm of SMOS over land, in order to provide information regarding vegetation and soil moisture over forested areas. Results presented in this paper were obtained using the last 620 version of the algorithm.

The correlation between the new vegetation optical depth (VOD) product and the height of the forest estimated by ICES at GLAS lidar on a global scale is investigated. Over South American and African forests a good correspondence between the two variables is observed, with saturation occurring above about $30 \mathrm{~m}$ height. Moreover, the comparison between the VOD and the height of the forest shows good spatial and temporal stability, and the $r^{2}$ correlation coefficient is within a 0.59-0.69 range. Conversely, discrepancies are observed in some Indonesian islands, particularly New Guinea. Over specific areas, the trends vs. forest height obtained with SMOS VOD are compared with the corresponding trends of AMSR-E VOD. Results are also validated at country-level scale. To this aim, accurate estimates of forest biomass derived from airborne lidar over selected forests of Peru, Columbia and Panama are used. Finally, the soil moisture retrieved over forests is investigated, reporting continental maps for Tropical areas and comparisons with ground measurements in selected forests of the US. Continental maps obtained with the new level 2 V620 algorithm cover almost all forest areas, and show seasonal variations which are dependent on climatic zones. Comparisons between soil moisture retrievals in forests and ground measurements of the US SCAN network produce worse RMSE values with respect to low vegetation areas. Significant improvements however are achieved after averaging among close nodes of the ground network.
\end{abstract}

\section{Introduction}

The Soil Moisture and Ocean Salinity (SMOS) mission is the second Earth Explorer Opportunity mission, launched in November 2009 by the European Space Agency (ESA) (Kerr et al., 2010). SMOS carries an L-band 2-D interferometric radiometer operating in the $1400-1427 \mathrm{MHz}$ protected band. At this frequency the wave penetrates well through the atmosphere, and hence the instrument probes the earth surface emissivity.

Over land, measured brightness temperatures are related to soil properties. Several investigations demonstrated that $\mathrm{L}$ band passive instruments obtained a high level of performance in retrieving soil moisture. It was found however, that surface roughness and vegetation cover also greatly influence the measurements (Ulaby \& Long, 2014; Wigneron et al., 2003). Their effects must be taken into consideration when a retrieval algorithm is developed. The dual polarization and multi-angular properties of the SMOS radiometer are unprecedented features and essential in order to solve the inverse problem of retrieving soil moisture (SM) and vegetation optical depth (VOD) from brightness temperature measurements. Over land, the SMOS retrieval algorithm is composed of a forward model, based on the zero order radiative transfer (RT) theory, and an iterative inversion procedure (Kerr et al., 2012). For soils covered by vegetation, soil moisture and vegetation optical depth are obtained as outputs by the level 2 (L2) algorithm. Other parameters, such as soil roughness and vegetation albedo, are fixed. Vegetation covers are subdivided into two main categories: short vegetation and forests. For short vegetation, scattering is assumed to be negligible and the albedo is set equal to zero. This approximation cannot be extended to forests, as several experiments and model investigations indicate (Ferrazzoli, Guerriero, \& Wigneron, 2002; Grant et al., 2008). In the SMOS algorithm, the albedo and the initial value of the optical depth are provided taking into account previous theoretical simulations and information extracted from the ECOCLIMAP database (Masson, Champeau, Chauvin, Meriguet, \& Lacaze, 2003), as detailed in Kerr et al. (2012). Theoretical simulations were tested over specific sites, but cannot account for local variations of forest parameters around the world and ECOCLIMAP itself cannot provide all the forest variables that influence the emissivity. Errors in initial values of the optical depth are corrected by the iterative retrieval algorithm, but the albedo 
and the soil roughness remain unchanged. Moreover, when forest cover is dominant within the pixel, the retrieval procedure is critical since the high attenuation produced by vegetation reduces the sensitivity to variations of soil moisture. As a consequence of all these problems and of the intrinsic inaccuracies of brightness temperature measurements, retrieving SM and VOD under forests is challenging, although it is important for several applications. In fact, the reliability of global climatic models depends on the quality of SM estimates for all land covers. Moreover, several forest problems such as degradation, stress, and fire risk, can be better understood and managed if reliable and timely information about forest SM is available (Kerr, Waldteufel, Richaume, Ferrazzoli, \& Wigneron, 2015). Forests are thick canopies, even at L band, so improvements in SM estimates can only be achieved if vegetation parameters are correctly estimated. This first reason for improving precision in VOD evaluation is important for SMOS as well as for other missions based on L-band measurements. Signatures collected by Aquarius instrument (Le Vine, Lagerloef, Colomb, Yueh, \& Pellerano, 2007), although dedicated to ocean applications, are also used over land, particularly in large homogeneous areas (Piles, McColl, Entekhabi, Das, \& Pablos, 2015), and SMAP is specifically employed for retrieving soil moisture over all land covers (Entekhabi et al., 2010).

VOD retrieval itself is also interesting since it contains important information about vegetation. Several previous studies, reviewed by Jackson and Schmugge (1991) and Van de Griend and Wigneron (2004), found significant relations between VOD and vegetation water content $\left(\mathrm{kg} / \mathrm{m}^{2}\right)$ for crops. In recent years, investigations have been extended to forests. Relevant experiments have been carried out using ground based radiometers, in both upward looking and downward looking configurations (Grant et al., 2008; Guglielmetti et al., 2007, 2008; Kurum, O'Neill, Lang, Cosh, \& Jackson, 2011; Santi, Paloscia, Pampaloni, \& Pettinato, 2009). Airborne radiometers have flown over forests with different properties (Macelloni, Paloscia, Pampaloni, \& Ruisi, 2001; Saleh et al., 2004; Vittucci et al., 2013). In parallel, the problem of forest emission has been investigated by model simulations (Ferrazzoli et al., 2002; Kurum et al., 2011, 2012). Although the experiments were carried out in different environments, some basic conclusions can be drawn. The emissivity of dense forests at $L$ band is in a $0.8-0.95$ range, significantly lower than the unity. Since in this case the emission is mostly contributed by volume, this means that volume scattering cannot be neglected. In addition, the retrieved VOD at L band is in a typical 0.5-1.2 range, values considerably higher than those retrieved for low vegetation. Moreover, it is mostly contributed by wood, and increases with wood biomass.

Monitoring forest properties using spaceborne missions, such as SMOS, is interesting for several reasons. Estimating forest biomass is a fundamental application of remote sensing. In certain favorable conditions, such as for low density of forests and absence of clouds, results can be obtained using well established optical instruments. For instance, significant correlations with biomass were achieved over boreal forests using the normalized difference vegetation index (NDVI) measured by the Advanced Very High Resolution Radiometer (AVHRR), cumulated over the growing season (Dong et al., 2003). However, global biomass maps or estimations over the dense tropical forests, require a synergic use of different instruments, i.e. optical radiometers and lidar (Baccini, Laporte, Goetz, Sun, \& Dong, 2008). Data from the Geoscience Laser Altimeter System (GLAS) onboard ICESat (Ice, Cloud, and land Elevation Satellite) opened the possibility to globally mapping the forest vertical structure at $1 \mathrm{~km}$ spatial resolution, as illustrated by the map of canopy height provided by Simard, Pinto, Fisher, and Baccini (2011). Satellite laser altimetry has a unique capability for estimating forest canopy height, which has a direct and well understood relationship with the carbon stored aboveground (Lefsky et al., 2005). However, GLAS collected data over a limited time period with discontinuous spatial coverage. Thus, in order to produce global maps, GLAS data must be joined with other, more spatially dense, ancillary variables available globally, such as forest type, tree cover, elevation, and climatology maps. In order to do this, products provided by other instruments, such as MODIS, are used (Lefsky et al., 2005; Simard et al., 2011). Radar measurements contain information directly related to the structure of the forest, thus being more correlated to parameters such as growing stock volume and biomass. Spaceborne radar sensors operating with long wavelengths are the most suitable for biomass mapping, since they have a higher penetration through the canopy, which is needed to sense the main biomass components of the forest. Experimental investigations however found that this technique also suffers from a limitation related to early saturation. Significant improvements have been obtained in boreal forests using $\mathrm{L}$ band time series and appropriate statistical techniques (Thurner et al., 2014), but the saturation limit does not exceed 50 $100 \mathrm{t} / \mathrm{ha}$. Several studies indicate that the saturation limit can be extended using a P band SAR (Santos et al., 2003) and related programs, such as BIOMASS of ESA, are being developed (Le Toan et al., 2011). However, using spaceborne systems available at the present time and in the near future, saturation of radar signals poses severe limitations. The potential use of surface reflectivity measurements provided by Global Navigation Satellite Systems (GNSS) is also under investigation. Some results are promising (Egido et al., 2014) but further studies are needed before the application can be mature.

In summary, several techniques for remote sensing of forest biomass have been proposed and tested, and important advances have been achieved from both a theoretical and operational point of view, but each technique shows limits in precision, sensitivity, revisit time, and biomass saturation level. Although several global datasets of forest height and forest biomass are presently adopted, predicted values are often different from each other (Ge, Avitabile, Heuvelink, Wang, \& Herold, 2014) since direct measurements are only available for specific sites and extension to wide areas shows some margins of uncertainty. Microwave radiometry, in spite of its coarse resolution, can be a useful tool for this application, possibly to be used in synergy with other data sources.

Products of spaceborne radiometers over forests have already been analyzed and used. Liu, de Jeu, McCabe, Evans, and van Dijk (2011) examined two decades of VOD products obtained by Advanced Microwave Scanning Radiometer (AMSR-E) and investigated the correlation with NDVI, which was considerable over grasslands and croplands, but was less significant over forests. The authors attributed this result to the different properties of the two indexes. While NDVI is fundamentally sensitive to chlorophyll and leaf biomass, VOD is considerably dependent on wood biomass and can be a useful indicator of deforestation processes. AMSR-E VOD was obtained using the algorithm proposed by Owe, de Jeu, and Walker (2001), using C and $\mathrm{X}$ band channels of AMSR-E. It is expected that L band radiometers, due to the higher penetration depth, will add useful information.

Relevant studies using SMOS data have already been published. Rahmoune et al. (2014) investigated the SMOS VOD product generated by the prototype $\mathrm{L} 2$ algorithm available in 2013 over forests, and found that it was significantly related to forest height, with low seasonal variations. Cui, Shi, Du, Zhao, and Xiong (2015) generated a VOD product using SMOS L1C data at horizontal polarization, the Advanced Integral Equation Method (AIEM) surface model for soil surface, and a simple radiative transfer model to represent vegetation. Over areas largely covered by forests, this product was correlated with wood biomass, and was less correlated with optical vegetation indexes, such as NDVI. More recently, global estimates of above ground biomass (biomass per unit surface, $t / h a$ ) for both forest and non-forest biomes during the past two decades were derived from an AMSR-E VOD dataset (Liu et al., 2015); this VOD-based multitemporal analysis allows us to understand trends of biomass vs. time and drivers of change considerably better.

The main goal of this research is to test the capability of SMOS L2 data to provide information related to vegetation and soil moisture over forested lands. Specific objectives include: (i) to test the last dataset produced with the new V620 version of the algorithm; (ii) to investigate the correlation between the new VOD product and forest height as estimated by other sensors (Simard et al., 2011); (iii) to compare SMOS trends vs. forest height with those of AMSR-E; (iv) to 


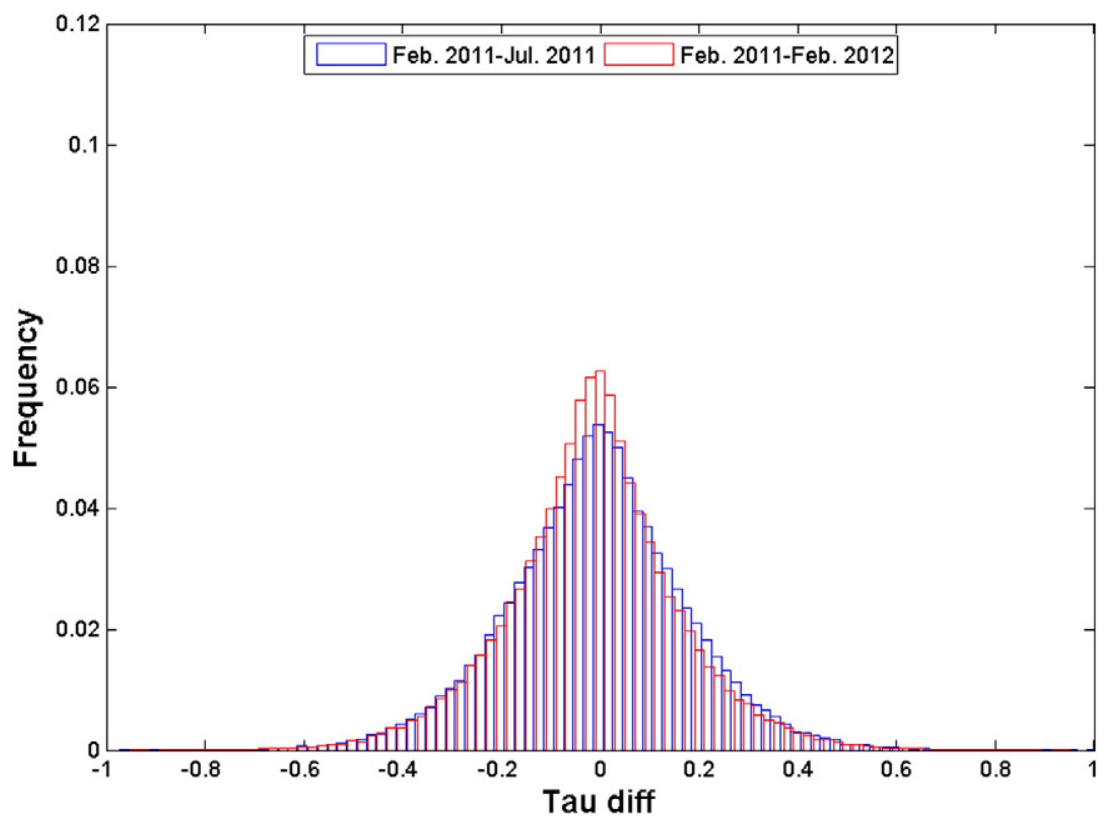

Fig. 1. Histograms of the differences between forest VOD in February 2011 and February 2012 (red), February 2011 and July 2011 (blue) for latitudes lower than $+20^{\circ}$.

investigate the correlation between VOD and accurate lidar-derived biomass estimations, for countries where these datasets are available (Peru, Columbia and Panama); (v) to test the soil moisture retrieval results in some forest areas.

The correlation between the new VOD product and forest height estimated by the map drawn up in the work of Simard et al. (2011) at a global scale is investigated, also analyzing the spatial and temporal stability of the relationships. Over specific areas and for the summer season, trends vs. forest height obtained with SMOS VOD are compared with the corresponding trends of AMSR-E VOD. SMOS VOD results are also validated at a country-level scale. In order to achieve this, accurate estimates of forest biomass derived from airborne lidar over selected forests of Peru, Columbia and Panama are used. Finally, the soil moisture retrieved over forests using V620 is investigated, reporting continental maps and comparisons with ground measurements in selected forest areas of the US.

\section{Materials and methods}

\subsection{SMOS data}

The L2 algorithm was described by Kerr et al. (2012), and details about the last version were given by Kerr et al. (2015). The new V620 version of brightness temperature (L1C) and retrieved SM and VOD (L2) data show several important changes with respect to the previous V551 release. In particular, the brightness temperatures have been reprocessed, in order to reduce the impact of spatial biases and other artifacts related to aperture synthesis technique, and the forward model

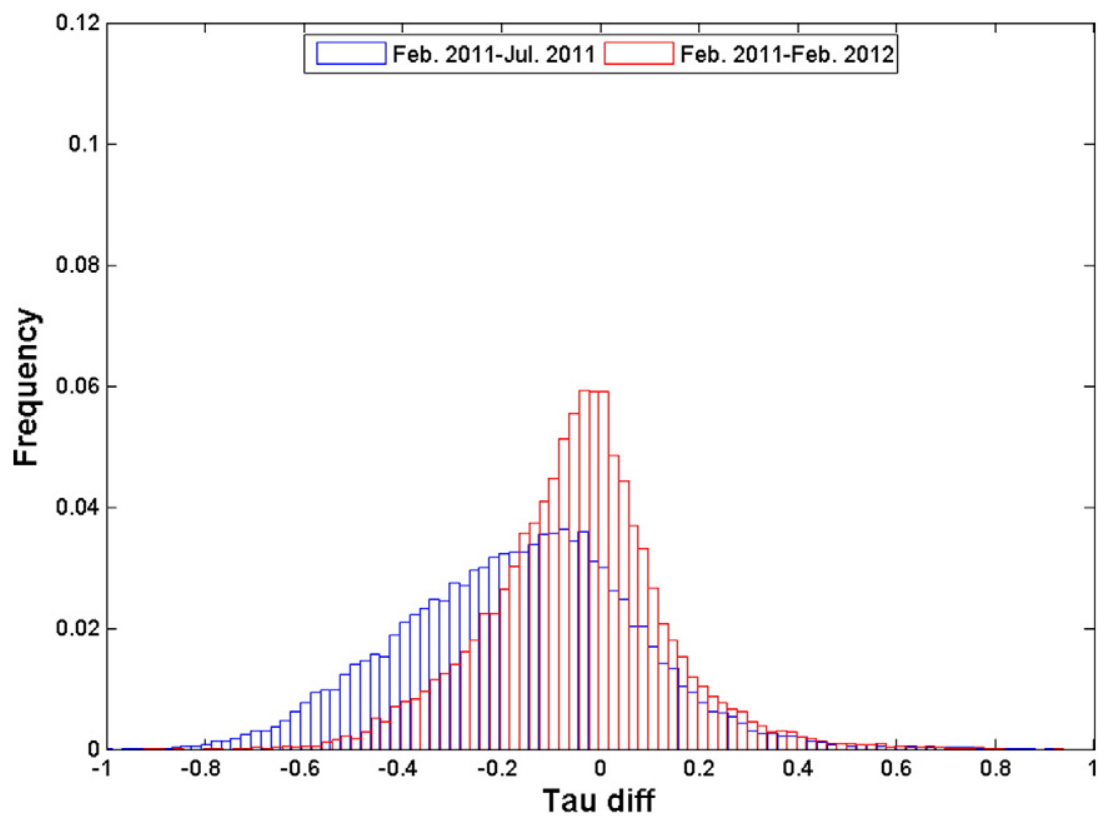

Fig. 2. Histograms of the differences between forest VOD in February 2011 and February 2012 (red), February 2011 and July 2011 (blue) for latitudes higher than $+20^{\circ}$. 
Table 1

Average values and spatial standard deviations of VOD for a dense Amazonian area $(-12$ latitude $<-10,-72<$ longitude $<-70$ ).

\begin{tabular}{lll}
\hline Dates & VOD mean & VOD standard deviation \\
\hline February 2011 & 1.036 & 0.124 \\
July 2011 & 1.057 & 0.112 \\
November 2011 & 1.033 & 0.114 \\
February 2012 & 1.150 & 0.103 \\
Average & 1.071 & 0.072 \\
\hline
\end{tabular}

has been reworked and refined. Further changes were applied to Radio Frequency Interference (RFI) detection, and some control criteria adopted by the iterative procedure retrieving SM and VOD from brightness temperature measurements. Finally, a new land use map has been used, including the latest version of ESA's GlobCover V2.3. Details are given by Kerr et al. (2015).

The fraction of forest area with retrieved SM and VOD available is extended with the V620 version of the algorithm, particularly in dense tropical forests, thus offering the conditions for retrieval quality evaluation.

At the time of this study only a partial dataset of V620 outputs was available, since the whole dataset was being reprocessed. The algorithm was globally tested for four 8-day time slots: 2011/02/06-2011/02/14 2011/07/01-2011/07/08, 2011/11/01-2011/11/08, 2012/02/01-2012/ $02 / 08$.

Results presented in this paper were obtained with V620, and are limited to SMOS pixels in which forest is the dominant cover, which means that the fraction of forest cover (FFO) is higher than $50 \%$. It must be stressed that the SMOS algorithm only retrieves the VOD $(\tau)$ of the dominant cover. We show comparisons between the VOD associated to each pixel with $\mathrm{FFO}>50 \%$ and parameters, such as forest height or biomass, obtained using data of different instruments and averaged over the same pixel. In order to make this comparison significant, an effective VOD was computed as the product between retrieved $\tau$ values and FFO. This is an approximation, since the brightness temperature of mixed pixels can be computed by averaging the contributions of single parts, but the relation between the brightness temperature and $\tau$ is not linear. We have checked that the errors of the applied linearization rarely exceed $3 \mathrm{~K}$. Moreover, the additional contribution of short vegetation, which is given by the product of its optical depth by its cover fraction, is neglected. However, since the optical depth of short vegetation is low (generally lower than about 0.3 ) and in the cases considered by us its fraction is lower than $50 \%$, this short vegetation contribution to VOD is very low with respect to the one due to forests.

\subsection{Forest height database (Simard et al., 2011)}

We compared the retrieved values of VOD with the forest heights provided by the global map of Simard et al. (2011). The motivation of this comparison is to verify the expected dependence of VOD on the total amount of vegetation matter, which on its turn is dependent on the vegetation height (Asner et al., 2012, 2013).

The Simard et al. (2011) map, at 1-km resolution, was generated using data collected in 2005 by GLAS. The GLAS estimate of canopy height is the waveform metric RH100, defined as the distance between signal beginning and the location of the lidar ground peak. GLAS footprints were approximately $65 \mathrm{~m}$ in diameter, spaced by $170 \mathrm{~m}$ along track and several tens of kilometers across track. The map was extended to areas not directly covered by lidar footprints by using the Random Forest (Breiman, 2001) model, including vegetation information from MODIS, additional elevation data from the Shuttle Radar Topography Mission (SRTM), and climatology information from both the Tropical Rainfall Measuring Mission (TRMM) and the Worldclim database. The resulting map was validated using field measurements from 66 FLUXNET sites (Baldocchi, 2008), where most forest heights ranged between 10 and $30 \mathrm{~m}$. A detailed description of the algorithm and relevant results is given by Simard et al. (2011), and the digital map is made available by NASA Earth Observatory (http://earthobservatory.nasa. gov/GlobalMaps/?eocn =topnav\&eoci=globalmaps). Recent global carbon databases, such as Tropical Forest Carbon Storage Map (Jet Propulsion Laboratory, JPL, http://carbon.jpl.nasa.gov/data/dataMain.cfm),

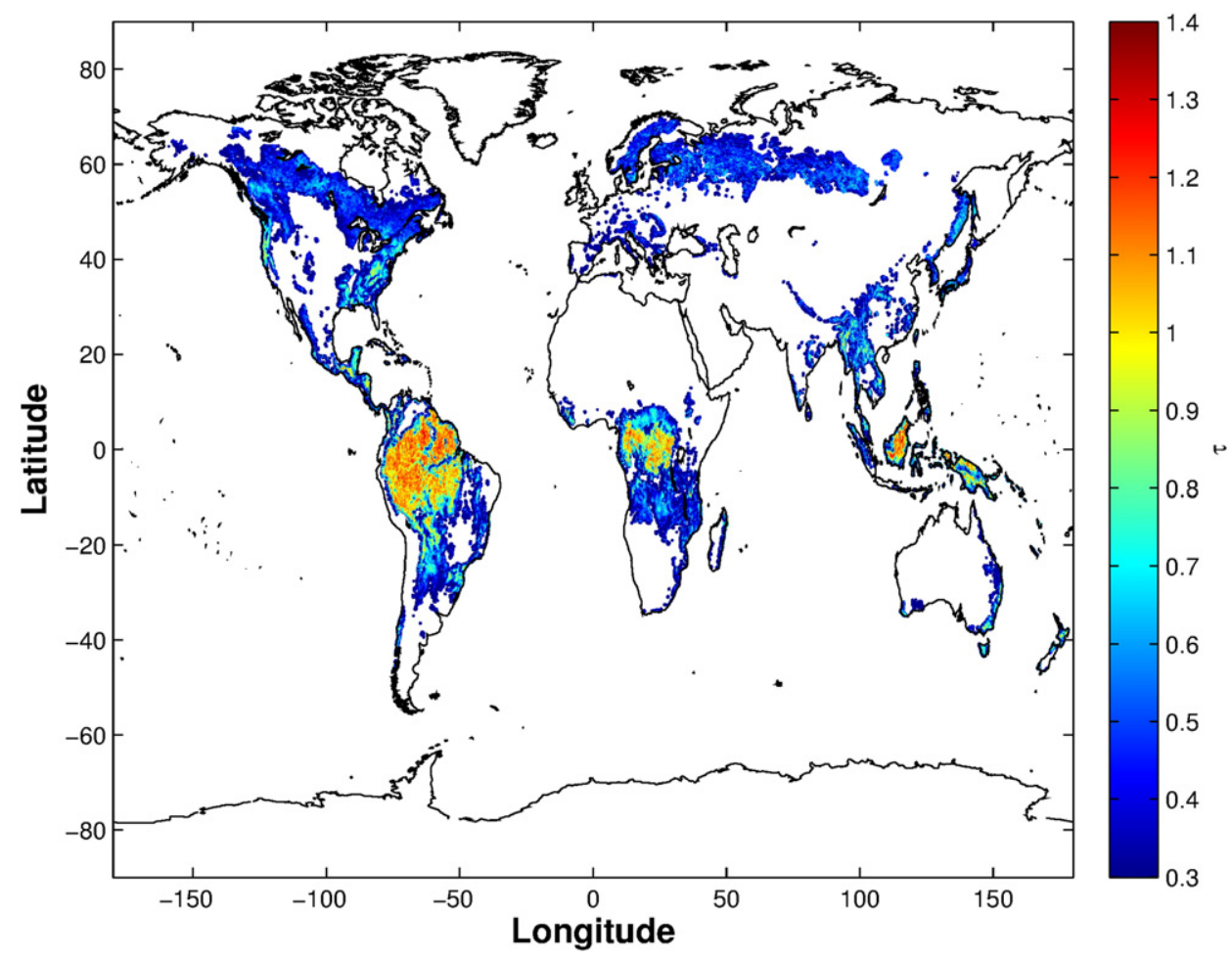

Fig. 3. Global map of forest VOD obtained after temporal averaging: i) using all the four available 8-day time intervals (for latitudes lower than $+20^{\circ}$ ); ii) only using July and November (for latitudes higher than $+20^{\circ}$ ). 

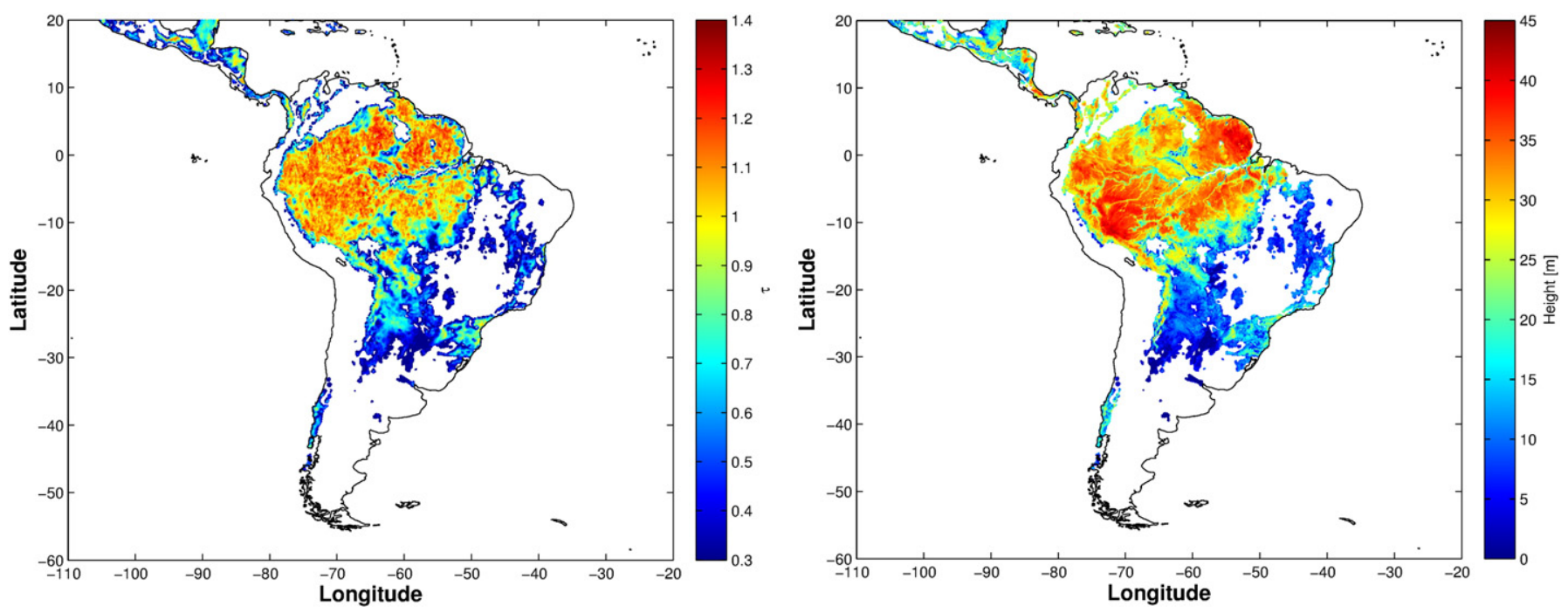

Fig. 4. South America. Left: Average SMOS VOD. Right: Forest height estimated by Simard et al. (2011).

the Pantropical National Level Carbon Stock Dataset (Woods Hole Research Center, WHRC, http://www.whrc.org/mapping/pantropical/ carbondataset_form.htm), and Geocarbon (http://www.bgc-jena.mpg. $\mathrm{de} / \mathrm{geodb} /$ ) adopted the forest height measured by GLAS as a primary source of information, confirming the validity of the Simard et al. (2011) dataset for comparison purposes. Since there are differences among the mentioned carbon databases, we preferred to adopt the GLAS height as a reference for comparisons with SMOS VOD.

In order to make the 1-km GLAS dataset comparable with SMOS spatial resolution, we applied a spatial resampling of the GLAS forest canopy heights on the SMOS ISEA4H9 (Icosahedral Snyder Equal Area Earth fixed) grid, characterized by equally spaced nodes at about $15 \mathrm{~km}$ distance (Kerr et al., 2012). The spatial resampling was carried out by averaging the forest height values for the GLAS pixels falling in each ISEA4H9 hexagonal cell. A source of uncertainty in our comparison could be represented by the 6 years of difference between SMOS and
ICEsat GLAS acquisitions; however this time gap is not too significant in mature and relatively undisturbed forests, characterized by climax conditions in which tree mortality equals recruitment and growth, producing a steady biomass level. This time difference can be more important in disturbed areas or secondary forests, and can partially be the cause of some disagreements observed between our results and the heights retrieved by Simard et al. (2011) (see Section 3.2).

The Simard et al. (2011) database also provides RMSE computed using the differences between Random Forest model estimates and direct lidar measurements, in areas where they were available; this information is given at $1^{\circ}$ resolution. For our comparison purposes, we selected areas with RMSE of forest height lower than $5 \mathrm{~m}$, but in the map representations all available data have been kept. A preliminary assessment was done by visually comparing the VOD-derived map and the Simard et al. (2011) forest height map, for different regions. Then, for a statistical analysis, the range of forest heights estimated by
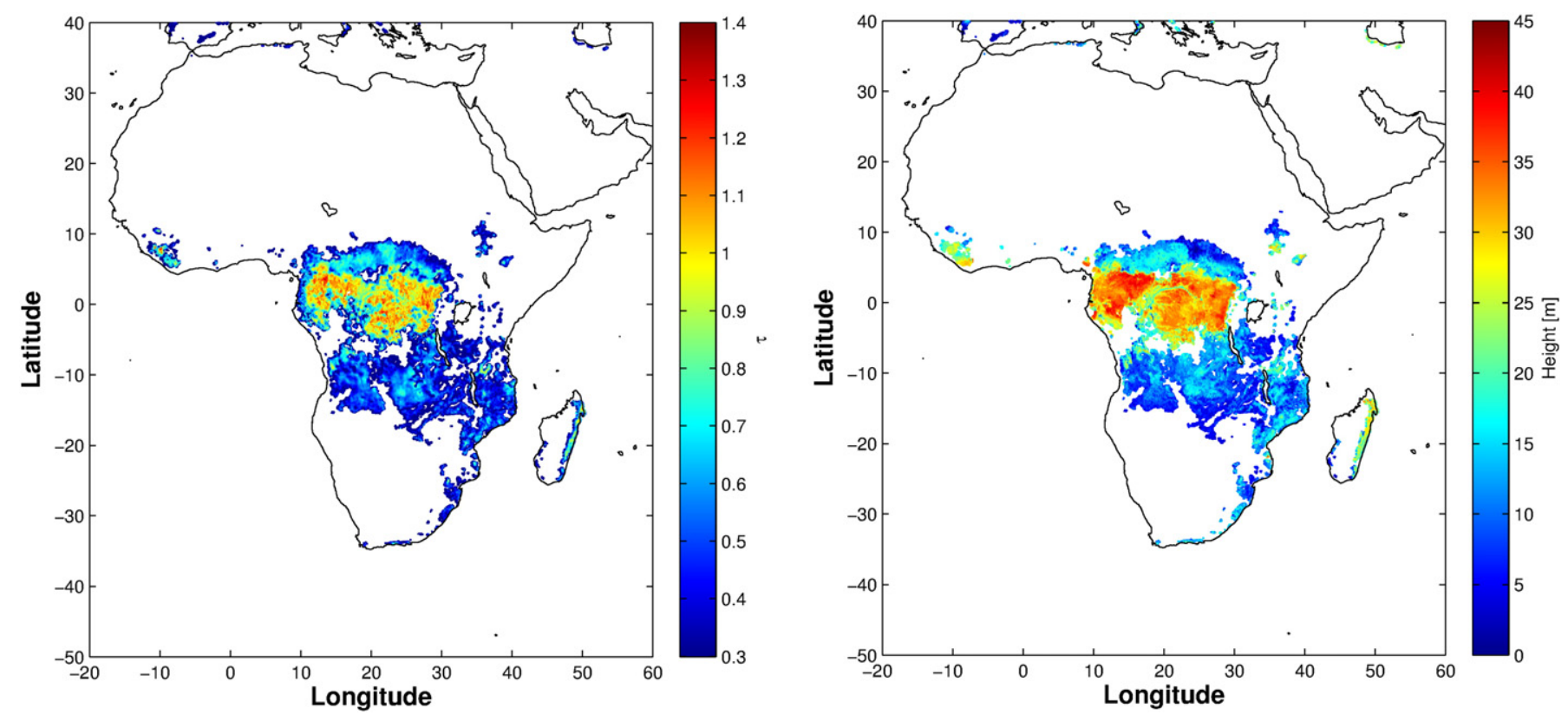

Fig. 5. Africa. Left: Average SMOS VOD. Right: Forest height estimated by Simard et al. (2011). 

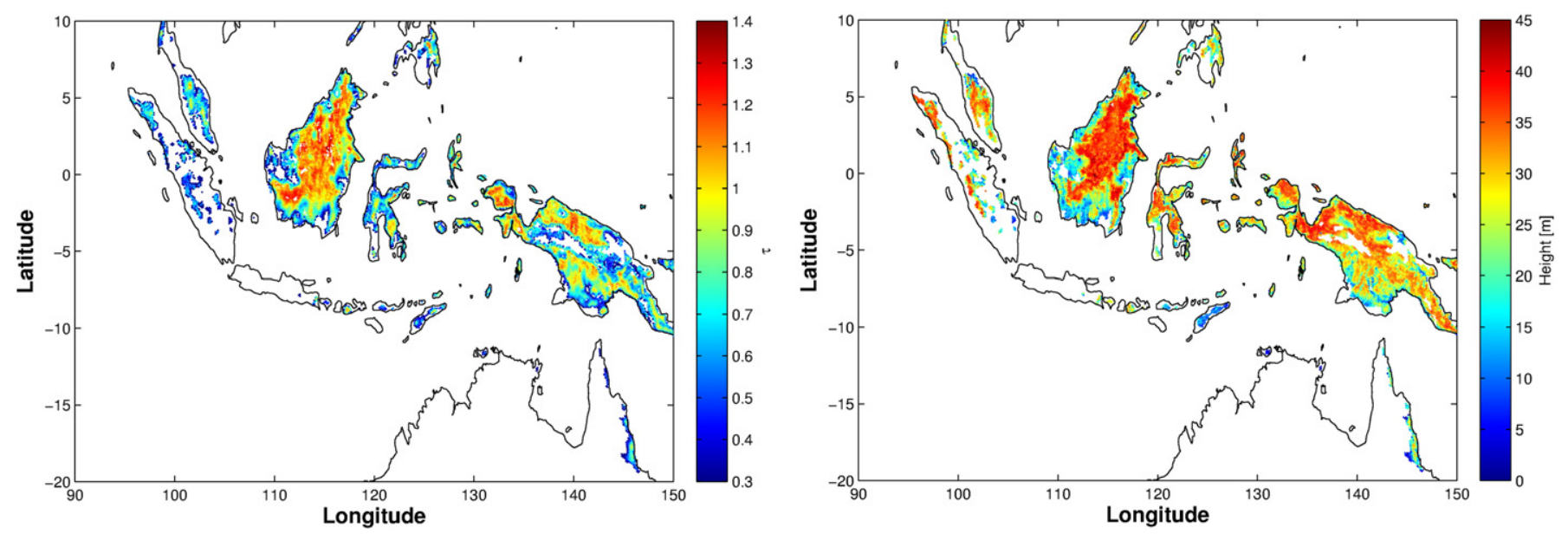

Fig. 6. Indonesia. Left: Average SMOS VOD. Right: Forest height estimated by Simard et al. (2011).

Simard et al. (2011) was divided into $2 \mathrm{~m}$ intervals: for each interval, the average and the standard deviation of SMOS VOD were computed.

Moreover, we considered the following linear regression:

$\tau=b^{\prime} H+b^{\prime \prime}$

$\tau$ is the VOD retrieved by SMOS, $H$ is the height estimated by Simard et al. (2011), $b^{\prime}$ and $b^{\prime \prime}$ are coefficients of the relation. For South America, the parameters of the linear regression have been computed using VOD for the single 8-day time intervals, and for the average values. For Africa and Indonesia, only averaged VOD values have been used.

The retrieval of the optical depth for the boreal region is more complex: the range of forest heights is more limited than in the tropical biome (rarely above $25 \mathrm{~m}$ ), and there are large climate variations that support many different ecosystems. Moreover, both needleleaf and broadleaf species are present. They are characterized by different deciduousness behavior, and averaging can be performed over 2 seasons only (July and November), since February data were often affected by snow. RFI effects are also more important in this region. For these reasons, at the present time a qualitative comparison is presented for the North America continent and it separately examines broadleaf and needleleaf forests. The separation of these two broad categories was done according to the ECOCLIMAP dataset.

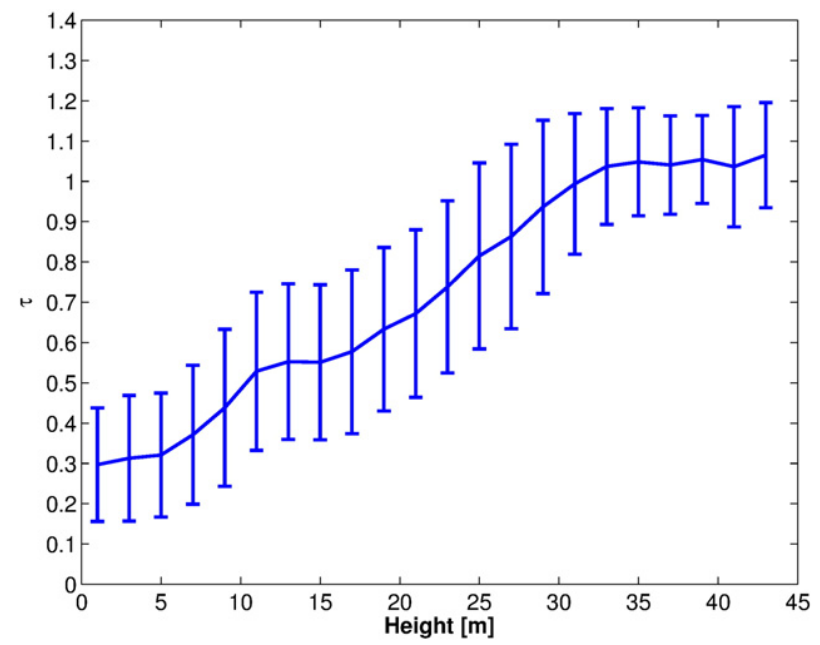

Fig. 7. Average optical depth versus forest height for forests of South America. Continuous line: VOD average for given forest height intervals of $2 \mathrm{~m}$. Error bars: standard deviation.

\subsection{AMSR-E database}

AMSR-E data collected in the recent decades have been used for long term investigations about retrieved SM and VOD. For forests, VOD resulted to be related to wood and leaf biomass (Liu et al., 2011), indicating that there is potential to monitor deforestation and growth processes. Since AMSR-E VOD was retrieved at $\mathrm{C}$ and $\mathrm{X}$ band, it is interesting to compare the results with $\mathrm{L}$ band results made available by SMOS. The higher penetration of $\mathrm{L}$ band can be used to add significant information to microwave radiometry for forest applications.

SMOS data used in this paper does not allow us to make long term investigations. However, a comparison between SMOS and AMSR-E VOD products can be appropriate to evaluate the potential application related to a synergic use of both instruments. In order to do this, we compared the trends vs. forest height of SMOS VOD averaged in 8 days of February 2011 and 8 days of July 2011 (16 days in total) against the corresponding trends of AMSR-E VOD retrieved by Land Parameter Retrieval Model (LPRM) (Owe et al., 2001), averaged in the same days. We were unable to extend the comparisons to subsequent dates due to unavailability of AMSR-E after October 2011. For each pixel of each instrument, we computed the average value of forest height by resampling GLAS data to the respective grid. Then we computed the average and standard deviation of VOD for $2 \mathrm{~m}$ intervals of forest height.

\subsection{Carnegie Airborne Observatory (CAO) regional database}

We also compared our VOD retrieved values with CAO products. Intensive lidar surveys over some South American forests were made using the Carnegie Airborne Observatory-2 Airborne Taxonomic Mapping System (AToMS; 12), which is carried onboard a twin turbopropeller Dornier 228 aircraft (Asner et al., 2014). To cover the maximum area per flight hour, the aircraft was operated at speeds up to 150 knots at an average altitude of $2000 \mathrm{~m}$ above ground level. Airborne lidar sampling was carried out using $100 \mathrm{~m} \times 100 \mathrm{~m}$ grid cells. On

Table 2

Results of statistical analysis over different dates for South America.

\begin{tabular}{llll}
\hline Dates & $b^{\prime}\left(\mathrm{m}^{-1}\right)$ & $b^{\prime \prime}$ & $r^{2}$ \\
\hline February 2011 & 0.023 & 0.25 & 0.61 \\
July 2011 & 0.024 & 0.23 & 0.66 \\
November 2011 & 0.021 & 0.28 & 0.59 \\
February 2012 & 0.023 & 0.27 & 0.62 \\
Average & 0.023 & 0.26 & 0.69 \\
\hline
\end{tabular}


Table 3

Results of statistical analysis for tropical forests.

\begin{tabular}{lllll}
\hline Area & $b^{\prime}\left(\mathrm{m}^{-1}\right)$ & $b^{\prime \prime}$ & $r^{2}$ & Number of pixels \\
\hline South America & 0.023 & 0.26 & 0.69 & 14298 \\
Africa & 0.020 & 0.22 & 0.59 & 10054 \\
Indonesia & 0.014 & 0.37 & 0.20 & 1576 \\
South America, Africa, and Indonesia & 0.022 & 0.23 & 0.62 & 25928 \\
\hline
\end{tabular}

average, about $6.5 \%$ of grid cell extension was covered by direct lidar measurements.

In this paper, we consider results collected during the surveys made between 2010 and 2012 over forests of Columbia (Asner et al., 2012), Panama (Asner et al., 2013) and Peru (Asner et al., 2014). Lidar measurements estimated the mean value of Top Canopy Height (TCH) for each hectare of lidar coverage. A full map coverage was generated using an environmental stratification approach, based on information about the fractional cover of photosynthetic and non-photosynthetic vegetation, topography, solar insolation and cloudiness. TCH data were converted into dry biomass using allometric equations calibrated over specific forest plots in which ground measurements were available. The datasets also provide associated uncertainty in biomass estimates.

Considering the high density of direct lidar measurements and the accuracy in lidar-derived biomass estimates, the CAO datasets are a valid reference for comparisons with SMOS VOD data.

Similarly to the case of comparisons with GLAS height, biomass values were averaged within the SMOS grid. Statistical comparisons suffered from some limitations related to the variability of land cover with respect to SMOS resolution. Since the areas with homogenous forest cover were mainly characterized by high biomass, the dynamic range of biomass available for comparison was limited. To mitigate this problem, we selected within the maps some extended areas, including spots with lower biomass. For each area, we computed the standard deviation of biomass measurements within SMOS pixels, and selected pixels satisfying the condition to have a standard deviation of estimated biomass lower than $50 \mathrm{t} / \mathrm{h}$. The aim was to obtain a trade-off between two requirements: the need to have pixels located in homogeneous areas, in order to mitigate mixed pixels problems, and the need to analyze a significant dynamic range of biomass.

\subsection{The SCAN network}

The SCAN network from the National Soil Survey Center (NRCS), USDA, gives free access to climatic station data across the U.S. (http:// www.wcc.nrcs.usda.gov) (Schaefer, Cosh, \& Jackson, 2007). The stations are equipped with several sensors, such as air temperature, relative humidity, SM at different depths, soil temperature at different depths, solar radiation, wind speed, and precipitation. The most important data for this study is the SM at 2 in. (50.8 mm), measured by Hydra
Probes. The SCAN data collection system provides near real-time data from remote sites (http://www.wcc.nrcs.usda.gov/ftpref/downloads/ factpub/soils/SNOTEL-SCAN.pdf).

The network was extensively used in previous research activities (De Lannoy, Ufford, Sahoo, Dirmeyer, \& Houser, 2011; Jackson et al., 2010). More recently, the outputs of this network were also used to compare ground measurements with SMOS retrieved SM values, mostly collected over agricultural fields (Al Bitar et al., 2012).

For some forest nodes of SCAN network, we compared SM measurements outputs with SMOS retrievals in the pixel with closest grid point For these pixels, a V620 dataset covering two years (from June 1, 2010 to May 31, 2011) was available.

\section{Results}

\subsection{Seasonal effects and global maps}

The V620 algorithm was run for four 8-day time intervals of February, July and November 2011, and February 2012. VOD outputs were averaged within each of the four time intervals.

First of all, seasonal effects were investigated by computing the histograms of the differences between measurements collected in February 2011 and July 2011. Histograms of the differences between February 2011 and February 2012 were also computed for comparison.

The results of the investigation on seasonal effects are reported in Figs. 1 and 2. For forests with latitude lower than $+20^{\circ}$ (mostly tropical and located in South America, Africa and Indonesia) both histograms are well peaked around zero (Fig. 1). Both average differences have an absolute value lower than 0.02 , suggesting that in this case seasonal effects are negligible. The standard deviations are 0.18 (for February 2011July 2011 difference) and 0.17 (for February 2011-February 2012 difference). For boreal forests with latitude higher than $+20^{\circ}$ (Fig. 2) the VOD's of July are slightly higher than the VOD's of February. This result can be partially explained by the behavior of deciduous forests in winter, but the effect is moderate. In fact, the average differences are -0.16 (for February 2011-July 2011) and -0.05 (for February 2011-February 2012), while the standard deviations are 0.24 and 0.18 , respectively. These numbers indicate that regular seasonal variations are low and differences are mostly due to random effects also at higher latitudes.

Results reported in Figs. 1 and 2 suggested the application of a further averaging among data collected in the four different seasons, in order to filter the noise. The advantages of this averaging were investigated by selecting a $2^{\circ} \times 2^{\circ}$ box of uniform dense forest in Amazonia. Box limits are $-10^{\circ}$ and $-12^{\circ}$ in latitude, $-70^{\circ}$ and $-72^{\circ}$ in longitude. In this area, the average forest height was $38.8 \mathrm{~m}$ and the standard deviation of forest height was $1.5 \mathrm{~m}$. The spatial average and the spatial standard deviation of VOD in the area for each season and for the temporal average are reported in Table 1. Since the area is homogeneous, the appreciable reduction of spatial standard deviation obtained by
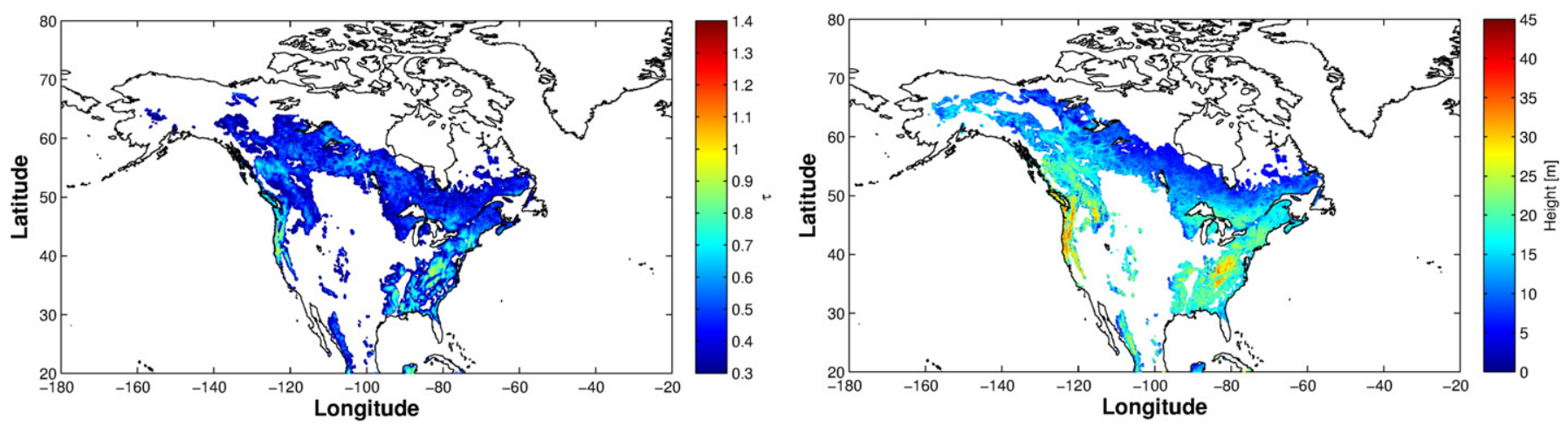

Fig. 8. North America. Left: Average SMOS VOD. Right: Forest height estimated by Simard et al. (2011). 

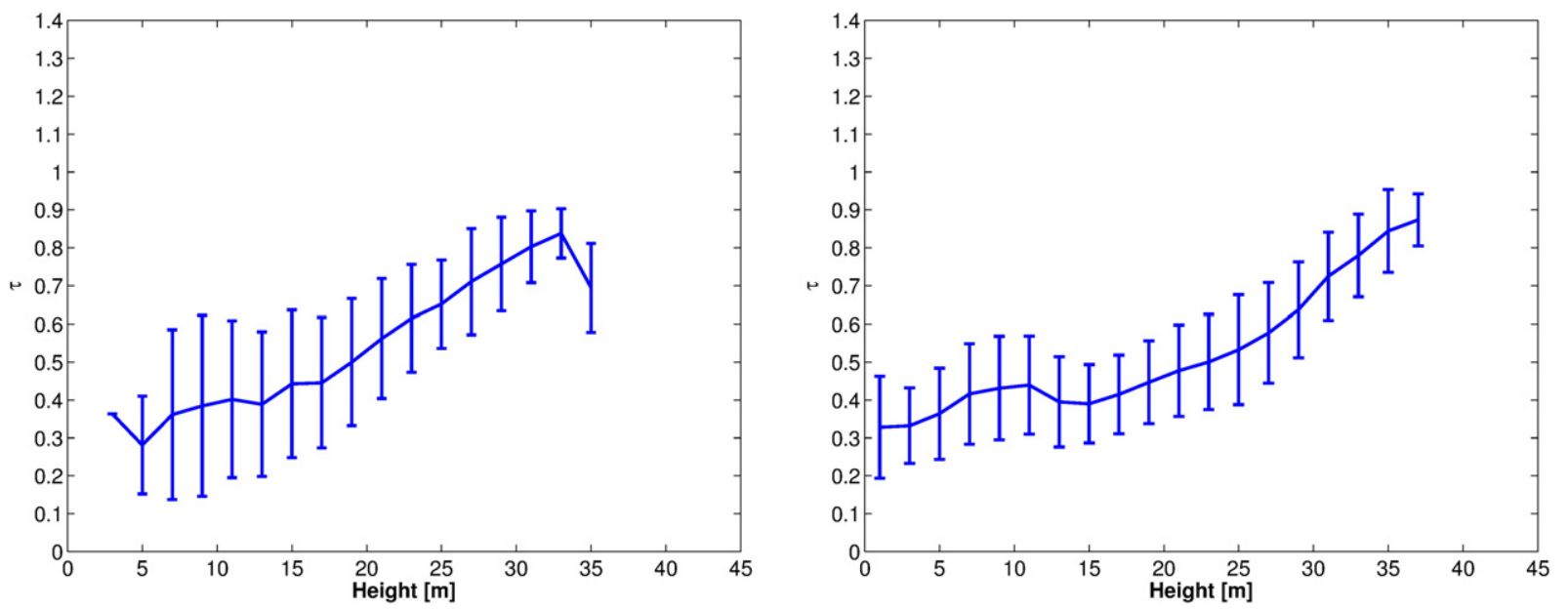

Fig. 9. Average optical depth versus forest height for broadleaf (left) and needleleaf (right) forests of North America. Continuous line: Average for given forest height intervals of 2 m. Error bars: Standard deviation.

temporal averaging indicates that this operation filters random variations due to noise in the measurements.

The following results were obtained after application of this temporal average. For tropical and subtropical forests VOD's were averaged using all four dates. In boreal forests however this operation would
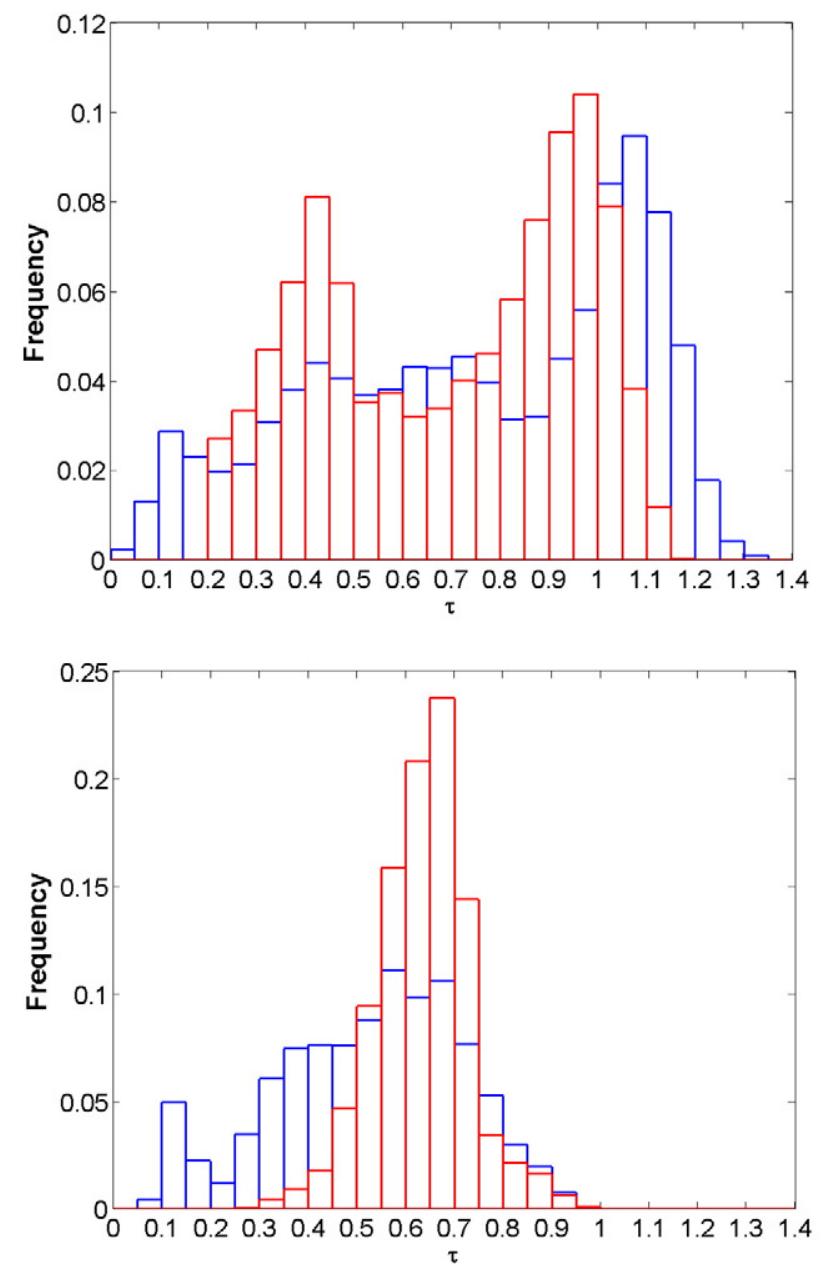

produce a strong reduction of pixels with available retrieval, due to snow effects in February; thus averaging was only applied between VOD's of July and November.

A global map obtained after averaging is reported in Fig. 3. As expected, the areas with the highest values of optical depth correspond
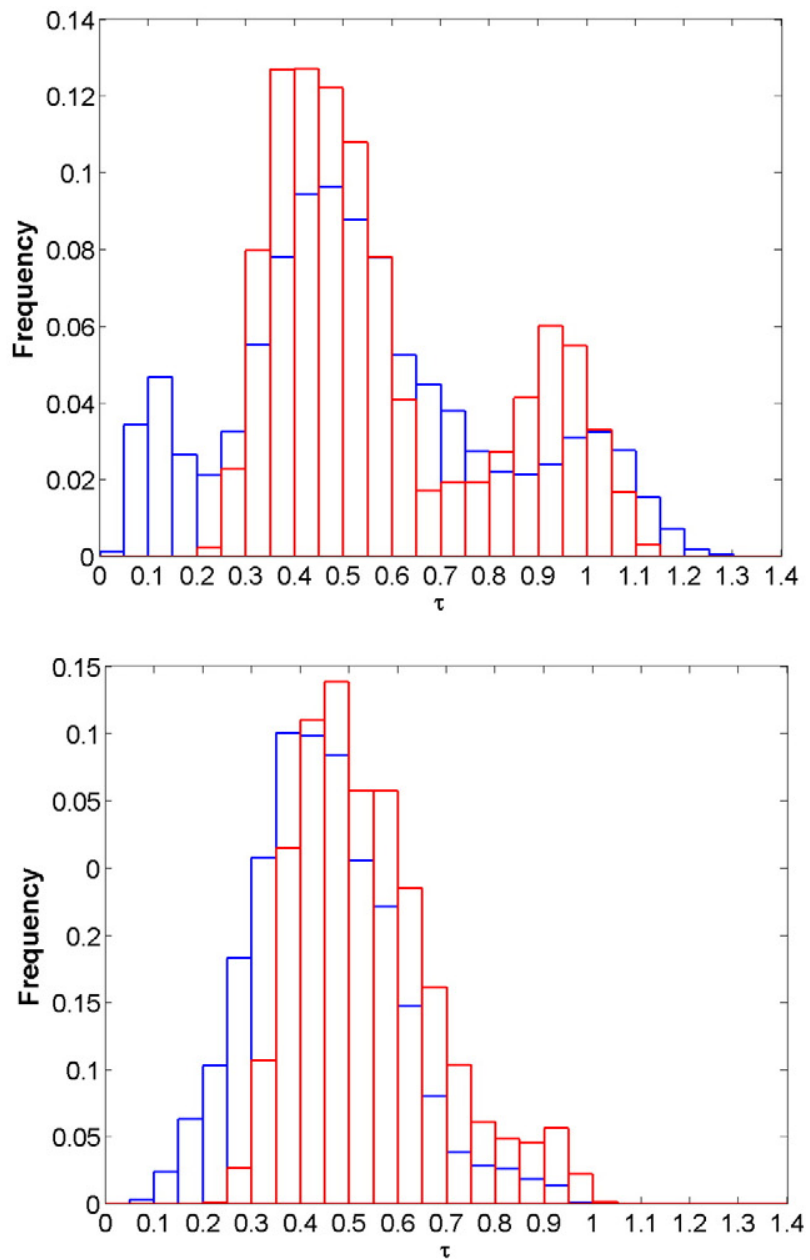

Fig. 10. Normalized distributions of VOD. Blue: Retrieved by SMOS. Red: Obtained by height measurements, Eq. (1) and coefficients reported in last line of Table 3. Top left: South America. Top right: Africa. Bottom left: North America broadleaf. Bottom right: North America needleleaf. 
to the dense tropical forests of the Amazonia and Congo basins, and of Borneo Island. Intermediate VOD values are observed in parts of boreal ranges in North America and Siberia.

\subsection{Comparison with forest height}

The VOD maps and the corresponding maps of forest height provided by Simard et al. (2011) are shown in Figs. 4 to 6 for South America, Africa and Indonesia, respectively.

In general, a good agreement between the spatial distributions of the retrieved VOD and the one of the forest height as modeled by Simard et al. (2011) is observed in the different continents (Figs. 4, 5, and 6). The large forest blocks in Africa, Borneo and South America are well identified in both datasets, as well as most of the areas with low vegetation height. At local level differences can also be observed, particularly in New Guinea. They may be attributable to many factors, including: the different spatial resolutions of the datasets provided by SMOS and Simard et al. (2011), the time gap between the datasets, the fact that the height we use for comparison is not a real ground truth but it is itself a modeled data, and data quality issues which affect both datasets. Additional research and validation is needed using local and more updated datasets, when available.

The results of the statistical comparison for the South American continent are shown in Fig. 7. A clear increasing trend of VOD vs. height is observed, with saturation reached above a height of about $30 \mathrm{~m}$, a threshold under which most of the forests are included.

Table 2 reports results of statistical analyses for each date, and averages among the dates, for all pixels of the South American continent; results include the $b^{\prime}$ and $b^{\prime \prime}$ linear regression coefficients, and the $r^{2}$ correlation coefficient between VOD and forest height. Little variation in $b^{\prime}$ and $b^{\prime \prime}$ coefficients is observed among dates, indicating a significant stability of the regression. The best correlation is obtained when the average $\tau$ is taken, since averaging produces noise filtering, as previously discussed. Statistical parameters were computed considering all pixels, including the ones with height above the saturation limit of $30 \mathrm{~m}$. Better correlation coefficients would be obtained by excluding pixels beyond this saturation limit. This can be the subject of future investigations.

A comparison with statistical results obtained by computing the temporal average of VOD data over all pixels of Africa and Indonesia is shown in Table 3. $b^{\prime}$ and $b^{\prime \prime}$ linear regression coefficients are close to the ones computed for South America, confirming the soundness of the $\tau$ vs. $H$ relationship in the tropical biome. The $r^{2}$ correlation coefficient computed for Africa is slightly lower than for South America, probably due to the heterogeneity of the African landscape compared to the South American one, with the former characterized by high fragmentation of land cover types and presence of several water bodies. We remark that in the previous versions of the algorithm, the water presence caused retrieval failures in extended areas of Congo (Rahmoune, Ferrazzoli, Kerr, \& Richaume, 2013). Discrepancies in New Guinea, already observed in Fig. 6, make the statistical metrics of Indonesia worse. This problem however affects about $6 \%$ of considered pixels, and produces a low impact on the global metrics shown in the last line of the table.

For all the cases reported in Table 3 the standard errors of the $b^{\prime}$ and $b^{\prime \prime}$ parameters are quite low. The standard error of $b^{\prime}$ ranges between a minimum of 0.0001 (for the South America area) and a maximum of 0.0007 (for the Indonesia area), while for $b^{\prime \prime}$ the standard error shows a minimum of 0.0027 (for the case of the last row of Table 3 ) and a maximum of 0.0199 (for the Indonesia area). The $t$-test with confidence intervals at $95 \%$ was performed for the four regressions recording in every instance $p$-values lower than 0.0001 for both parameters.

The qualitative comparison between North America maps is reported in Fig. 8: the Simard et al. (2011) map is characterized by a height gradient from South to North, while the SMOS VOD map shows a more complex shape.
For North America, averaged values and standard deviation of SMOS VOD, as a function of forest height intervals, are reported in Fig. 9, in which broadleaf and needleleaf forests have been separately examined. In both cases an increasing trend of VOD vs. forest height is only apparent above a height of about $15 \mathrm{~m}$.

In Fig. 10, normalized distributions of SMOS VOD are compared against distributions of VOD computed using forest height measurements and the regression Eq. (1), with coefficients reported in the last line of Table 3. For South America, the distribution of VOD derived by height measurements is clearly bimodal, while the SMOS VOD distribution only shows a clear peak around 1.1, with a smoothed trend in the range of lower values. This difference is mostly produced by subtropical forests with lower height but appreciable density, and will need specific investigations, possibly based on local information. For broadleaved forests of North America the SMOS VOD histogram is broader than the histogram obtained by height measurement. This can be due to the variability of forest properties, not fully explained by height variations. For African forests and needleleaf forests of North America the two distributions show similar shapes.

\subsection{Comparison with AMSR-E}

The comparison between trends vs. forest height of SMOS VOD and AMSR-E VOD is reported in Fig. 11 for forests of South America. In a range of forest height between 0 and $15 \mathrm{~m}$ the AMSR-E VOD is higher and increases with higher slope. However, higher increases of the SMOS VOD are observed in a range between 15 and $30 \mathrm{~m}$, and the differences become small when the forest height exceeds about $30 \mathrm{~m}$. Most probably, for low heights AMSR-E is probing the canopy and SMOS is still affected by surface uncertainties (SM, roughness, understory), while for higher values the SMOS VOD is more sensitive to forest height and less affected by surface uncertainties. Overall, the SMOS VOD shows a higher linear correlation coefficient ( $0.67 \mathrm{vs.} 0.60$ of AMSR-E), a higher $b^{\prime}$ slope $\left(0.023 \mathrm{~m}^{-1}\right.$ vs. $0.014 \mathrm{~m}^{-1}$ of AMSR-E) and a lower $b^{\prime \prime}$ intercept ( 0.25 vs. 0.56 of AMSR-E). The intercept $b^{\prime \prime}$ is mostly due to understory vegetation, made of leaves and small twigs (short vegetation), which is also present for low forest height. The intercept is higher at $\mathrm{C}$ band, since the attenuation of short vegetation increases with frequency (see, e.g. Jackson \& Schmugge, 1991). Conversely, branch attenuation is also important at $\mathrm{L}$ band, as demonstrated by experimental results over defoliated trees (Guglielmetti et al., 2007; Santi et al., 2009) and theoretical simulations (Ferrazzoli \& Guerriero, 1996). This explains the low difference between AMSR-E and SMOS VODs observed for higher forests, and the higher slope $b^{\prime}$ of SMOS VOD. All these results however need to be confirmed and further investigated by long term comparisons.

\subsection{Comparisons with CAO biomass database}

Fig. 12 reports the comparison between the map of SMOS VOD and the map of biomass estimated over Peru, Columbia, and Panama. A general qualitative agreement is observed.

SMOS pixels were selected in order to mitigate mixed pixels problems but keeping the biomass range sufficiently wide to perform a significant statistical regression. We selected the 20 locations marked in Fig. 12 (right). For each marked area, we considered the SMOS pixels surrounding the mark, and selected two pixels with the lowest standard deviation of lidar biomass measurements within the pixel area. The scatterplot of VOD vs. biomass estimated by CAO is reported in Fig. 13. An $r^{2}$ correlation coefficient of 0.74 was obtained.

For pixels with a biomass estimated by CAO higher than $200 \mathrm{t} / \mathrm{ha}$, the fraction of forest cover (FFO provided by SMOS L2 data) is in a range $85 \%-100 \%$ and the standard deviation is in a range $10-30 \mathrm{t} /$ ha for most of the samples. Lower values of biomass are present in areas of fragmented landscape, in which the minimum fraction of forest cover FFO is $72 \%$, and the standard deviation can increase up to $50 \mathrm{t} / \mathrm{ha}$. For 


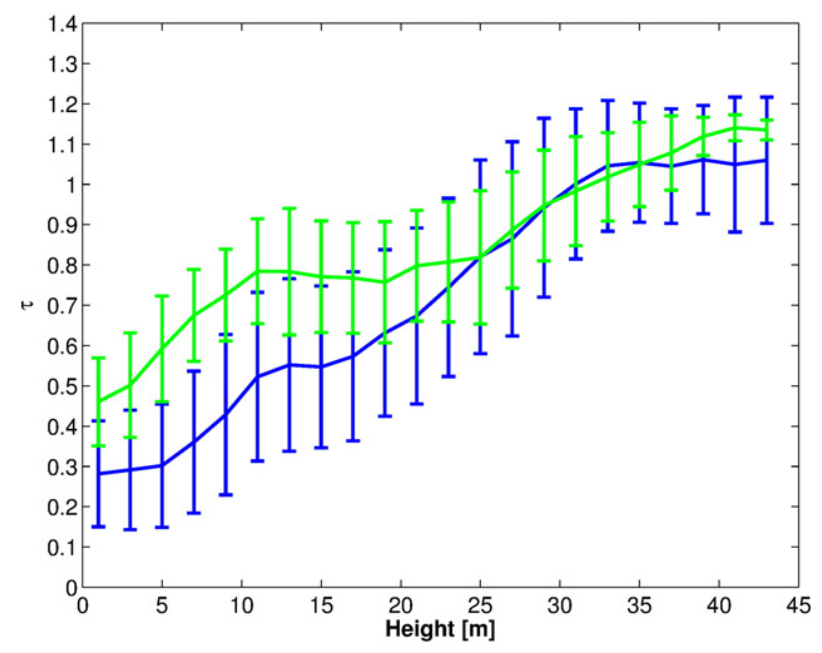

Fig. 11. Optical depth estimated by SMOS (blue) and AMSR-E (green) in February and July 2011 versus forest height for forests of South America. Continuous line: average for given forest height intervals of $2 \mathrm{~m}$. Error bars: Standard deviation.

areas located in Peru, an estimate of the biomass uncertainty is provided by Asner et al. (2014). This uncertainty is higher in heterogeneous areas. Averaging among the six samples with biomass lower than $100 \mathrm{t} / \mathrm{ha}$, the average standard deviation of biomass within the SMOS pixel is $45.6 \mathrm{t} / \mathrm{ha}$ and the average uncertainty is $59.6 \mathrm{t} / \mathrm{ha}$. Averaging over all other samples the corresponding values are $23.5 \mathrm{t} / \mathrm{ha}$ and $26.9 \mathrm{t} / \mathrm{ha}$, respectively. These data suggest that samples with lower biomass must be considered with some caution.

\section{Soil moisture}

Maps of retrieved soil moisture for South American and African continents are reported in Fig. 14. Only pixels with forest cover fraction FFO $>50 \%$ were considered. For each pixel, the temporal average of SM was computed for the two 8-day periods of February and July 2011. FFO maps are reported for reference.

Seasonal variations are observed, particularly for latitudes below about $-10^{\circ}$. These regions are classified as Tropical Savannah and Temperate with Dry Winter (Peel, Finlayson, \& Mc Mahon, 2007). Here high values of SM are retrieved in February (local Summer), while dryer

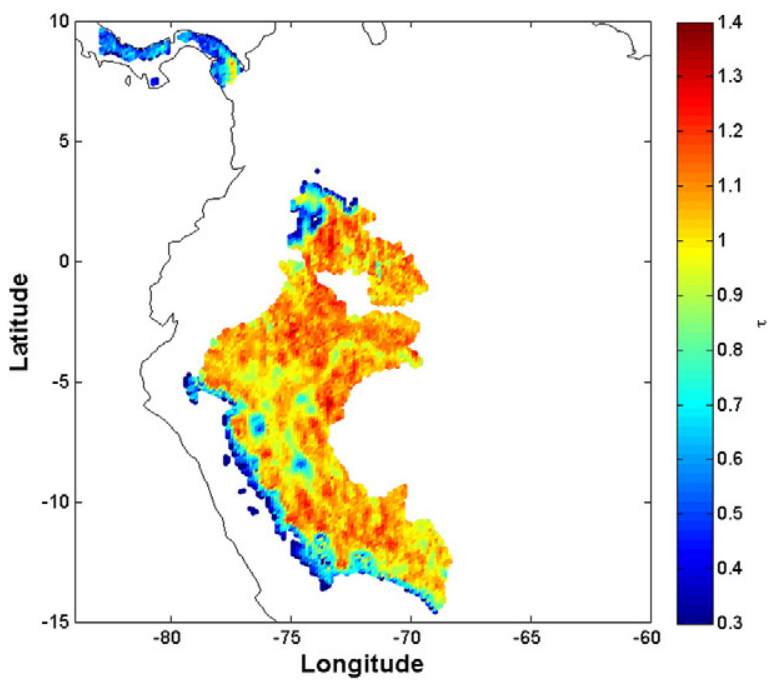

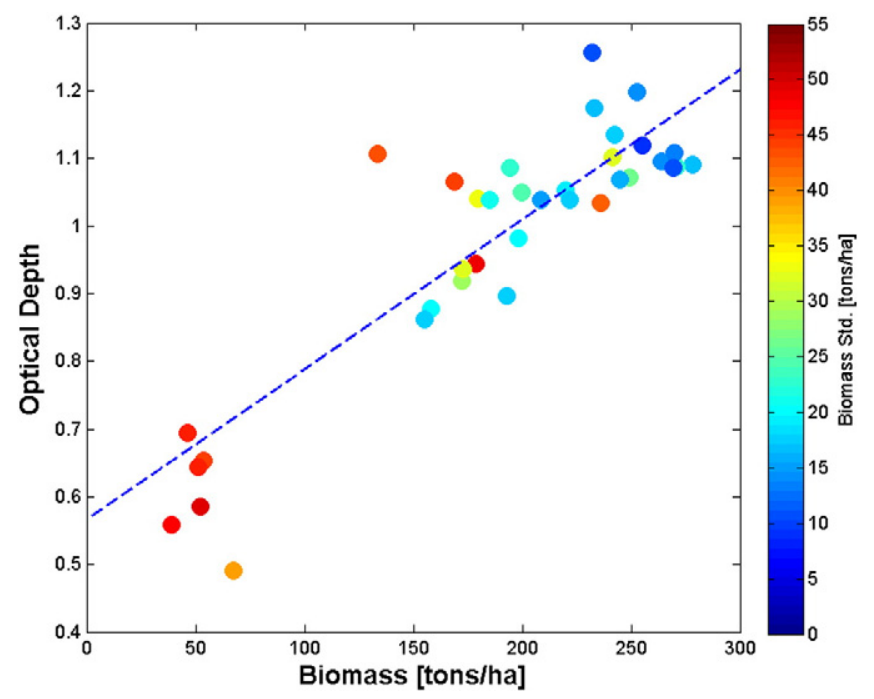

Fig. 13. Scatterplot of retrieved SMOS VOD vs. forest biomass. Color codes indicate the standard deviation of biomass measured by lidar within SMOS pixels. The correlation coefficient $r^{2}$ is 0.74

conditions are observed in July. In the dense forests of Amazonia and Congo, monitoring SM variations is difficult due to a high canopy attenuation, but local variations are also detected there.

Of course, it is not possible to test the reliability of observed seasonal variations at global level. For some SMOS forest pixels located in proximity of SCAN nodes, the V620 algorithm was run for two years, from June 1, 2010, to May 31, 2012. A statistical comparison between measured and retrieved SM values was made. Results for available SMOS pixels with forest fraction higher than $70 \%$ are reported in Table 4. For each node, the RMSE error $\left(\mathrm{m}^{3} / \mathrm{m}^{3}\right)$, the bias $\left(\mathrm{m}^{3} / \mathrm{m}^{3}\right)$ and the linear correlation coefficient are given. The number of available samples with ground measurements (N1), the number of valid retrievals (N2) and the range of forest fraction FFO are also reported.

A similar investigation was carried out using a previous prototype algorithm, and results were reported by Rahmoune et al. (2014). Better statistical coefficients were obtained in that study, but the number of valid retrievals was remarkably lower.

Results of the present investigation are worse than the ones generally obtained over low vegetation pixels (Kerr et al., 2012). This was expected, since the sensitivity to variations of soil moisture is reduced by

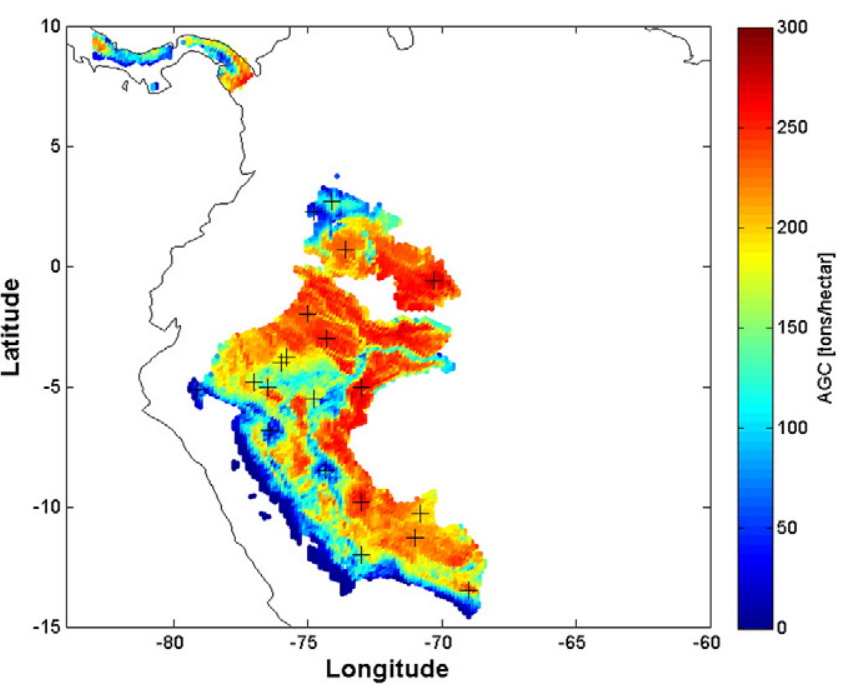

Fig. 12. Maps of SMOS VOD (left) and biomass estimated by airborne lidar CAO measurements (right) over Peru, Columbia, and Panama. Areas selected for statistical analysis are crossmarked in the right panel. 

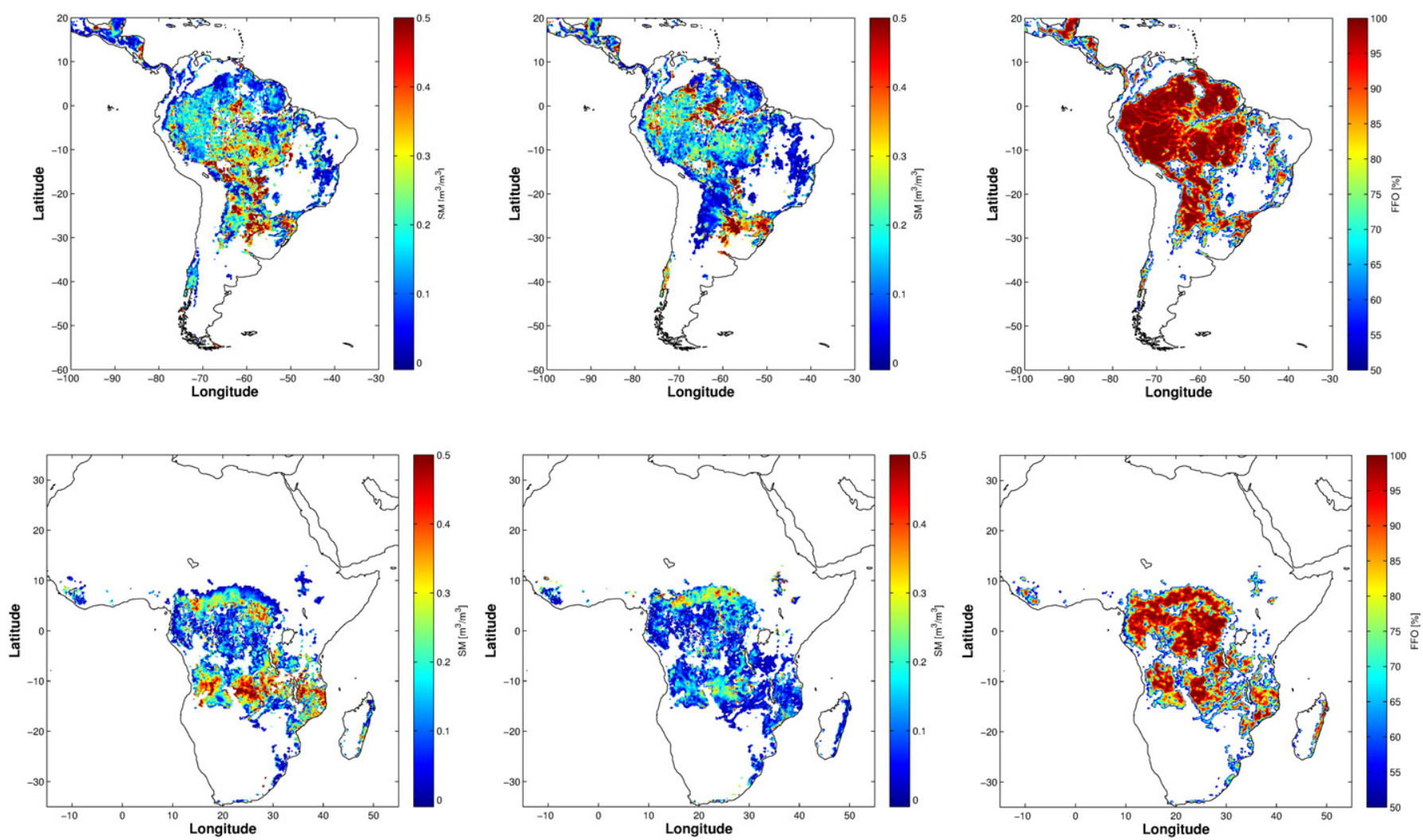

Fig. 14. Maps of retrieved SM $\left(\mathrm{m}^{3} / \mathrm{m}^{3}\right)$ in forest areas with FFO > 50\% for 8-day intervals. Left: SM in February 2011. Middle: SM in July 2011. Right: forest fraction FFO (\%). Top: South America. Bottom: Africa.

the higher canopy attenuation. For low vegetation the optical depth rarely exceeds values of about $0.3-0.4$, which are considerably lower than the ones reported in Fig. 8. Moreover some model parameters, such as forest albedo and soil roughness factor are fixed, and their estimates can be affected by errors. Also the quality of brightness temperature data is not perfect, although it is improved in version V620. Mixed pixels represent a further issue, as discussed by Kerr et al., 2012, and this is confirmed by results of Table 4, where worst values of bias and RMSE are obtained for $\mathrm{FFO}<80 \%$. Problems however can be also related to the insufficient spatial sampling of ground SM measurements, which were made in a single location per SMOS pixel and can be unable to represent the average SM within the extended pixel area. In order to investigate this problem of spatial sampling, we considered two adjacent SCAN nodes (2113 and 2179) and we compared the time series obtained by averaging measurements in the two nodes against the average of retrieved SM among three SMOS pixels with FFO higher than $80 \%$ located in proximity of the line joining the two SCAN nodes. After this averaging, which included a total of 168 temporal samples, the RMSE and the bias were reduced to 0.068 and 0.003 , respectively, and the correlation coefficient was 0.64 .

Deeper investigations will be made in the future using long term V620 data, in order to consider extended time intervals, and a complete spatial coverage of SMOS pixels in the US and other countries with available ground data.

\section{Discussion and conclusions}

This paper presented results obtained by the SMOS V620 retrieval algorithm over land. In particular, two applications have been tested: the retrieval of the vegetation optical depth, for its possible usefulness in relationship to biomass monitoring, and of soil moisture over forested land. The first application is in scope with the L2 SM algorithm, although correlation with forest biomass was not yet investigated. The second application is an extension of original scopes. In fact, the retrieval accuracy for soil moisture was only specified for surfaces where the vegetation water content was lower than $5 \mathrm{~kg} / \mathrm{m}^{2}$. Over forested areas this threshold corresponds to a dry biomass of about $50 \mathrm{t} / \mathrm{ha}$, and is exceeded in most cases.

The potential use of VOD data has been evaluated by means of comparisons with a global dataset of forest height obtained by ICESat GLAS spaceborne lidar, and with a regional dataset obtained by CAO airborne lidar. A significant linear correlation between the SMOS VOD and the forest height was obtained in tropical forests of South America and Africa, which contain very dense forest and retain a large part of the world biomass. The linear relationship between VOD and height resulted to be stable with respect to both temporal and spatial variations, and saturation was only observed for heights above $30 \mathrm{~m}$. Tests with high accurate airborne lidar measurements collected over tropical forests of South America confirmed this trend.

Table 4

Statistical comparison between retrieved SM and SCAN measurements.

\begin{tabular}{llllllll}
\hline Site name & $\begin{array}{l}\text { Site } \\
\text { ID }\end{array}$ & $\begin{array}{l}\text { RMSE } \\
\left(\mathrm{m}^{3} / \mathrm{m}^{3}\right)\end{array}$ & $\mathrm{R}$ & $\begin{array}{l}\text { Bias } \\
\left(\mathrm{m}^{3} / \mathrm{m}^{3}\right)\end{array}$ & $\mathrm{N} 1$ & $\mathrm{~N} 2$ & FFO (\%) \\
\hline Mahantango Ck & 2028 & 0.118 & 0.406 & 0.0004 & 607 & 135 & $70-80$ \\
Stanley Farm & 2056 & 0.122 & 0.742 & 0.0574 & 503 & 124 & $70-80$ \\
Shenandoah & 2088 & 0.196 & 0.227 & 0.0816 & 388 & 20 & $70-80$ \\
Cullman-NAHRC & 2113 & 0.113 & 0.619 & 0.0836 & 518 & 257 & $70-80$ \\
Livingston-UWA & 2114 & 0.204 & 0.357 & 0.1638 & 500 & 107 & $70-80$ \\
Rock Springs Pa & 2036 & 0.118 & 0.287 & 0.0237 & 516 & 182 & $80-90$ \\
Wedowee & 2175 & 0.110 & 0.331 & 0.0702 & 471 & 142 & $80-90$ \\
Wabeno \#1 & 2003 & 0.090 & 0.355 & 0.0500 & 595 & 110 & $90-100$ \\
Hytop & 2054 & 0.118 & 0.538 & 0.0584 & 648 & 248 & $90-100$ \\
Hubbard Brook & 2069 & 0.110 & 0.108 & 0.0659 & 769 & 152 & $90-100$ \\
Reynolds Homestead & 2089 & 0.106 & 0.393 & -0.010 & 698 & 329 & $90-100$ \\
Sudduth Farms & 2179 & 0.117 & 0.653 & -0.091 & 652 & 374 & $90-100$ \\
\hline
\end{tabular}


These results display the potential of long term retrievals of SMOS VOD as a tool for monitoring changes of forest biomass at global scale.

A comparison of the trends of VOD vs. forest height obtained using SMOS and AMSR-E indicates that the resulting trends are generally similar, but SMOS VOD shows a higher slope in the 15-30 m range of forest height, and thus has higher sensitivity in this height interval. Therefore, the availability of SMOS retrieved VOD can increase the range of datasets available for forest monitoring, particularly for highly dense forests, where biomass estimation is more critical. Continental maps of soil moisture show seasonal variations which are dependent on climatic zones. Appreciable SM variations were found in some areas, even with dense forest coverage. Comparisons between SM retrievals in forests and ground measurements of US SCAN network give worse RMSE values with respect to low vegetation areas. This result was expected due to the higher canopy attenuation. The comparisons however can be influenced by insufficient spatial sampling of ground data. In conclusion, the SMOS data and applications here explored can represent valuable information, also to quantify forest carbon and detect its changes. They can be used in synergy with other datasets, each characterized by specific benefits and limitations, at least till dedicated missions, such as the ESA Biomass Explorer and DLR Tandem-L, will be fully operational.

\section{Acknowledgments}

Work partially supported by European Space Agency under Contract 4000101152/10/I-AM, "SMOS Expert Laboratories (ESL) for the period 2010-2014 - ESL Soil Moisture" and by the Centre National d'Etudes Spatiales (CNES) programme TOSCA (Terre Océan Surfaces Continentales Atmosphère).

G.V.L. thanks the EU for supporting the BACI project funded by the EU's Horizon 2020 Research and Innovation Programme under grant agreement 640176.

\section{References}

Al Bitar, A. Leroux, D., Kerr, Y. H., Merlin, O., Richaume, P., Sahoo, A \& Wood, E. F. A. (2012). Evaluation of SMOS soil moisture products over continental U.S. using the SCAN/SNOTEL network. IEEE Transactions on Geoscience and Remote Sensing, 50 1572-1586.

Asner, G. P., Clark, J. K., Mascaro, J., Galindo Garcia, G. A., Chadwick, K. D., Navarrete Encinales, D. A . Ordonez, M. F. (2012). High-resolution mapping of forest carbon stocks in the Colombian Amazon. Biogeosciences, 9, 2683-2696. http://dx.doi.org/10. 5194/bg-9-2683-2012 (www.biogeosciences.net/9/2683/2012/).

Asner, G. P., Knapp, D. E., Martin, R. E., Tupayachi, R., Anderson, C. B., Mascaro, J., ... Silman, M. R. (2014). Targeted carbon conservation at national scales with high-resolution monitoring. Proceedings of the National Academy of Sciences of the United States of America. http://dx.doi.org/10.1073/pnas.1419550111.

Asner, G. P., Mascaro, J., Anderson, C., Knapp, D. E., Martin, R. E., Kennedy-Bowdoin, T., .. Bermingham, E. (2013). High-fidelity national carbon mapping for resource management and REDD +. Carbon Balance and Management, 8, 7 (http://www.cbmjournal. com/content/8/1/7)

Baccini, A., Laporte, N., Goetz, S. J., Sun, M., \& Dong, H. (2008). A first map of tropica Africa's above-ground biomass derived from satellite imagery. Environmental Research Letters, 3. http://dx.doi.org/10.1088/17489326/3/4/045011.

Baldocchi, D. (2008). 'Breathing' of the terrestrial biosphere: lessons learned from a global network of carbon dioxide flux measurement systems. Australian Journal of Botany, $56,1-26$.

Breiman, L. (2001). Random forests. Machine Learning, 45, 5-32.

Cui, Q., Shi, J., Du, J., Zhao, T. \& Xiong, C. (2015). An approach for monitoring global vegetation based on multiangular observations from SMOS. IEEE Journal of Selected Topics in Applied Earth Observations and Remote Sensing, 8, 604-616.

De Lannoy, G. J. M., Ufford, J., Sahoo, A. K., Dirmeyer, P., \& Houser, P. R. (2011). Observed and simulated water and energy budget components at SCAN sites in the lowe Mississippi Basin. Hydrological Procedure, 25, 634-649.

Dong, J., Kaufmann, R. K., Myneni, R. B., Tucker, C. J., Kauppi, P. E., Liski, J., ... Hughes, M. K. (2003). Remote sensing estimates of boreal and temperate forest woody biomass: Carbon pools, sources and sinks. Remote Sensing of Environment, 84, 393-410.

Egido, A., Paloscia, S., Motte, E., Guerriero, L., Pierdicca, N., Caparrini, M., ... Floury, N. (2014). Airborne GNSS-R polarimetric measurements for soil moisture and above ground biomass estimation. IEEE Journal of Selected Topics in Applied Earth Observations and Remote Sensing, 7, 1522-1532.

Entekhabi, D., Njoku, E. G., O'Neill, P. E., Kellogg, K. H., Crow, W. T., Edelstein, W. N., ... Van Zyl, J. (2010). The soil moisture active passive (SMAP) mission. Proceedings of the IEEE 98, 704-716.
Ferrazzoli, P., \& Guerriero, L. (1996). Passive microwave remote sensing of forests: A model investigation. IEEE Transactions on Geoscience and Remote Sensing, 34, 433-443.

Ferrazzoli, P., Guerriero, L., \& Wigneron, J. -P. (2002). Simulating L-band emission of forests in view of future satellite applications. IEEE Transactions on Geoscience and Remote Sensing, 40, 2700-2708.

Ge, Y., Avitabile, V., Heuvelink, G. B. M., Wang, J., \& Herold, M. (2014). Fusion of pan-tropical biomass maps using weighted averaging and regional calibration data. International Journal of Applied Earth Observation and Geoinformation, 31, 13-24.

Grant, J. P., Saleh, K., Wigneron, J. -P., Guglielmetti, M., Kerr, Y. H., Schwank, M., ... Van de Griend, A. A. (2008). Calibration of the L-MEB model over a coniferous and a deciduous forest. IEEE Transactions on Geoscience and Remote Sensing, 46, 808-818.

Guglielmetti, M., Schwank, M., Mätzler, C., Oberdörster, C., Vanderborght, J., \& Flühler, H. (2007). Measured microwave radiative transfer properties of a deciduous forest canopy. Remote Sensing of Environment, 109, 523-532.

Guglielmetti, M. Schwank, M., Mätzler, C., Oberdörster, C., Vanderborght, J., \& Flühler, H. (2008). FOSMEX: Forest soil moisture experiments with microwave radiometry. IEEE Transactions on Geoscience and Remote Sensing, 46, 727-735.

Jackson, T. J., \& Schmugge, T. J. (1991). Vegetation effects on the microwave emission of soils. Remote Sensing of Environment, 36, 203-212.

Jackson, T. J., Cosh, M. H., Bindlish, R., Starks, P. J., Bosch, D. D., Seyfried, M., ... Du, J. (2010). Validation of advanced microwave scanning radiometer soil moisture products. IEEE Transactions on Geoscience and Remote Sensing, 48, 4256-4272.

Kerr, Y. H., Waldteufel, P., Richaume, P., Wigneron, J. -P., Ferrazzoli, P., Mahmoodi, A., . Delwart, S. (2012). The SMOS soil moisture retrieval algorithm. IEEE Trans. Geosci. Remote Sens., 50, 1384-1403.

Kerr, Y. H., Waldteufel, P., Wigneron, J. -P., Delwart, S., Cabot, F., Boutin, J., ... Mecklenburg S. (2010). The SMOS mission: New tool for monitoring key elements of the global water cycle. Proceedings of the IEEE, 98, 666-687.

Kerr, Y. Waldteufel, P. Richaume, P., Ferrazzoli, P. \& Wigneron, J. -P. (2015). SMOS level 2 processor soil moisture algorithm theoretical basis document (ATBD): SO-TN-ARR-L2PP0037 v3.9. Toulouse, SM-ESL (CBSA). (http://smos.array.ca/web/smos/documentation or https://earth.esa.int/web/guest/-/data-processors-7632).

Kurum, M., O'Neill, P. E., Lang, R. H., Cosh, M. H., \& Jackson, T. J. (2011). A first-orde radiative transfer model for microwave radiometry of forest canopies at L-band. IEEE Transactions on Geoscience and Remote Sensing, 49, 3167-3179.

Kurum, M., O'Neill, P., Lang, R., Joseph, A., Cosh, M., \& Jackson, T. J. (2012). Effective tree scattering and opacity at L-band. Remote Sensing of Environment, 118, 1-9.

Le Toan, T., Quegan, S., Davidson, M. W. J., Balzter, H., Paillou, P., Papathanassiou, K. Ulander, L. (2011). The BIOMASS mission: Mapping global forest biomass to bette understand the terrestrial carbon cycle. Remote Sensing of Environment, 115 $2850-2860$.

Le Vine, D. M., Lagerloef, G. S. E., Colomb, F. R., Yueh, S. H., \& Pellerano, F. A. (2007). Aquarius: An instrument to monitor sea surface salinity from space. IEEE Transactions on Geoscience and Remote Sensing, 45, 2700-2708.

Lefsky, M. A., Harding, D. J., Keller, M., Cohen, W. B., Carabajal, C. C., Del Bom Espirito-Santo, F., ... de Oliveira, R., Jr. (2005). Estimates of forest canopy height and aboveground biomass using ICESat. Geophysical Research Letters, 32, L22S02. http://dx.doi.org/10.1029/2005GL023971.

Liu, Y. Y., de Jeu, R. A. M., McCabe, M. F., Evans, J. P., \& van Dijk, A. I. J. M. (2011). Global long-term passive microwave satellite-based retrievals of vegetation optical depth. Geophysical Research Letters, 38, L18402. http://dx.doi.org/10.1029/2011GL048684.

Liu, Y. Y., van Dijk, A. J. M., de Jeu, R. A. M., Canadell, J. G., McCabe, M. F., Evans, J. P., \& Wang, G. (2015). Recent reversal in loss of global terrestrial biomass. Nature Climatic Change Letters. http://dx.doi.org/10.1038/NCLIMATE2581 (published on line on 30 March 2015, www.nature.com/natureclimatechange).

Macelloni, G., Paloscia, S., Pampaloni, P., \& Ruisi, R. (2001). Airborne multifrequency L- to Ka-band radiometric measurements over forests. IEEE Transactions on Geoscience and Remote Sensing, 39, 2507-2513.

Masson, V., Champeau, J. -L., Chauvin, F., Meriguet, C., \& Lacaze, R. (2003). A global data base of land surface parameters at $1 \mathrm{~km}$ resolution in meteorological and climate models. Journal of Climate, 16, 1261-1282.

Owe, M de Jeu, R. A. M \& Walker J (2001). A methodology for surface soil moisture and vegetation optical depth retrieval using the microwave polarization difference index. IEEE Transactions on Geoscience and Remote Sensing, 39, 1643-1654.

Peel, M. C., Finlayson, B. L., \& Mc Mahon, T. A. (2007). Updated world map of the Koppen-Geiger climate classification. Hydrology and Earth System Sciences, $11,1633-1644$.

Piles, M., McColl, K. A., Entekhabi, D., Das, N., \& Pablos, M. (2015). Sensitivity of aquarius active and passive measurements temporal covariability to land surface characteristics. IEEE Transactions on Geoscience and Remote Sensing, 53, 4700-4711.

Rahmoune, R., Ferrazzoli, P., Kerr, Y. H., \& Richaume, P. (2013). SMOS level 2 retrieval lgorithm over forests: Description and generation of global maps. IEEE Journal of Selected Topics in Applied Earth Observations and Remote Sensing, 6, 1430-1439.

Rahmoune, R., Ferrazzoli, P., Singh, Y. K., Kerr, Y. H., Richaume, P., \& Al Bitar, A. (2014) SMOS retrieval results over forests: Comparisons with independent measurements. IEEE Journal of Selected Topics in Applied Earth Observations and Remote Sensing, 7, 3858-3866.

Saleh, K., Wigneron, J. -P., Calvet, J. C., Lopez-Baeza, E., Ferrazzoli, P., Berger, M., ... Miller, J. (2004). The EuroSTARRS airborne campaign in support of the SMOS mission: First results over land surfaces. International Journal of Remote Sensing, 25, 177-194.

Santi, E., Paloscia, S., Pampaloni, P., \& Pettinato, S. (2009). Ground-based microwave investigations of forest plots in Italy. IEEE Transactions on Geoscience and Remote Sensing, 47, 3016-3025.

Santos, J. R., Freitas, C. C., Araujo, L. S., Dutra, L. V., Mura, J. C., Gama, F. F., ... Sant'Anna, S. J S. (2003). Airborne P-band SAR applied to the aboveground biomass studies in the Brazilian tropical rainforest. Remote Sensing of Environment, 87, 482-493. 
Schaefer, G. L., Cosh, M. H., \& Jackson, T. J. (2007). The USDA natural resources conservation service soil climate analysis network (SCAN). Journal of Atmospheric and Oceanic Technology, 24, 2073-2077.

Simard, M., Pinto, N., Fisher, J. B., \& Baccini, A. (2011). Mapping forest canopy height globally with spaceborne lidar. Journal of Biophysical Research, 116, G04021.

Thurner, M., Beer, C., Santoro, M., Carvalhais, N., Wutzler, T., Schepaschenko, D., ... Schmullius, C. (2014). Carbon stock and density of northern boreal and temperate forests. Global Ecology and Biogeography, 23, 297-310.

Ulaby, F. T., \& Long, D. G. (Eds.). (2014). Microwave radar and radiometric remote sensing. Ann Arbor (US): The University of Michigan Press.
Van de Griend, A. A., \& Wigneron, J. -P. (2004). The b-factor as a function of frequency and canopy type at H-polarization. IEEE Transactions on Geoscience and Remote Sensing, 42 786-794

Vittucci, C., Guerriero, L., Ferrazzoli, P., Rahmoune, R., Tanase, M., Panciera, R., ... Walker, J. P. (2013). Airborne forest monitoring during SMAPEx-3 campaign. Proceedings of IEE International Geoscience and Remote Sensing Symposium (IGARSS), 987-990. http://dx. doi.org/10.1109/IGARSS.2013.6721328 (2013).

Wigneron, J. -P., Calvet, J. -C., Pellarin, T., Van de Griend, A. A., Berger, M., \& Ferrazzoli, P. (2003). Retrieving near-surface soil moisture from microwave radiometric observations: Current status and future plans. Remote Sensing of Environment, 85, 489-506. 